\title{
Competition in Taxes and Performance Requirements for Foreign Direct Investment ${ }^{*}$
}

\author{
Ronald B. Davies ${ }^{* *}$ and Christopher J. Ellis \\ University of Oregon
}

June 2001

Revised: January 2002

\begin{abstract}
Tax incentives offered to attract firms engaged in foreign direct investment are often tied to performance requirements such as domestic content restrictions. The tax competition literature has repeatedly shown that competition between municipalities for mobile firms tends to drive taxes to low levels. One would expect a comparable result for burdensome performance requirements. Despite this, the evidence suggests that while taxes have indeed been driven down, performance requirements are as popular as ever. We explain this seeming conundrum by showing that in the presence of spillovers, binding performance requirements can act as a coordination device for firms. In equilibrium, municipalities choose performance requirements which maximize joint surplus from investment. Competition between municipalities then transfers this surplus to firms via tax subsidies.
\end{abstract}

JEL Classification: F21, F23, H25.

Key words: Foreign direct investment, tax competition, domestic content requirements.

\footnotetext{
Any errors or omissions are the responsibility of the authors.

** Corresponding author: 533 PLC Building, 1285 University of Oregon, Eugene, OR, 97403. Phone: (541) 346-4671, Fax: (541) 346-1243, E-mail: rdavies@oregon.uoregon.edu
} 


\section{Introduction.}

Of the many policy tools available to manipulate foreign direct investment (FDI), two of the most prominent are taxes and performance requirements such as domestic content requirements. As Graham (2000) notes, both tax subsidies and performance requirements are frequently used by both developed and developing nations. Often these tax subsidies are directly contingent on the multinational firm satisfying various performance requirements (MITI, 2000). While tax competition between locations for FDI has been widely studied, we are unaware of any work which considers competition in performance requirements. As Wilson's (1999) survey highlights, tax competition models frequently predict a “race to the bottom" in which taxes are set lower than the host would like. This occurs as potential locations undercut one another in attempts to attract mobile investment. On the surface, one would expect a similar result for performance requirements, because if firms find these requirements burdensome, they will encourage competition which will eliminate their imposition. However, as Graham points out, in practice the result is much the opposite. Indeed he finds that both tax breaks for FDI and performance requirements are as popular as ever. This poses a conundrum: why are taxes bid away while performance requirements are not?

We seek to resolve this issue by suggesting that while from the perspective of any individual firm performance requirements may not be viewed as beneficial, it may still be the case that from the joint perspective of all the firms and the municipality they may be highly desirable. One of the most highly touted benefits of FDI is that it creates spillovers. These spillovers include worker training which benefits future employers, technology transfer, improved efficiency of local input providers, and a host of other mechanisms. Helleiner (1989) and Caves (1993) summarize a variety of evidence that points to the importance of spillovers. A recent example is found in Okamoto (1999), who showed that U.S. suppliers with ties to Japanese automakers have total factor productivity growth rates 8.9 percent higher than comparable firms. Okamoto attributes part of this productivity gain to technological diffusion from the 
Japanese firms to their domestic counterparts. When there are multiple firms, the effects of one firm may interact and reinforce the spillovers caused by others. Examples of this include agglomeration benefits which are increasing in industry output, a host country labor market with an upward-sloping supply curve, and the competitive effects in an oligopolistic market. Since firms do not internalize all of the effects of their actions, this can lead to individual firms making inefficient choices relative to the social optimum. Performance requirements, which often specify local employment and training levels, research requirements, and percentages of local content, coordinate firms on actions that maximize the total rents. The maximized rents generated by multinational activity are then extracted by the firms through competitively set tax subsidies. Thus, in equilibrium, generous tax packages will be offered at the same time as performance requirements are imposed. This is exactly the pattern described by Graham (2000), MITI (2000), and Moran (1998). The low tax rates are also indicative of the "race to the bottom" predicted by many models of tax competition for FDI. Of particular interest is that the equilibrium performance requirements are socially efficient in a variety of settings.

While to our knowledge there is no work examining competitively set performance requirements, the interaction between foreign firms operating under performance requirements and domestic firms has received considerable attention. Grossman (1981), Richardson (1991), Fung (1994), and Madan (1998) are amongst the contributors to this rich literature. They all study mechanisms by which the choices of multinational firms can impact the profitability and performance of domestic firms. In this literature, the contribution of Lahiri and Ono (1998) is closest to our own. They examine how a small host country can use a combination of income taxes and domestic content requirements to determine the number of multinational firms it attracts. FDI benefits the host through employment effects and via the endogenous price of an oligopolistic, non-traded good. They find that a tax on FDI is optimal only when the ratio of domestic to foreign input is sufficiently high. By considering a small host, they treat the firms' outside options as exogenous, and do not consider inter-jurisdictional competition for firms. We develop a 
multiple jurisdiction framework for which the Lahiri and Ono setting is a special case. Endogenous outside options lead to an equilibrium in which the performance requirements are set to maximize total surplus, yet much of this surplus is redistributed to firms via tax subsidies. Thus while we show that the Lahiri and Ono result holds for a partial equilibrium analysis, the gains to the host can evaporate in an more general setting.

We proceed as follows. In Section II we present the basic model and our main results. In Section III we extend the basic model in several ways and verify the robustness of the results. Section IV concludes.

\section{The Basic Model}

Consider a setting with two jurisdictions and two firms. Jurisdictions and firms are indexed by superscripts $\mathrm{j}=1,2$ and subscripts $\mathrm{i}=1,2$ respectively. Initially, we assume that jurisdictions are identical. The firms are indexed such that if they enter sequentially then firm 1 enters first. In the first stage of the game, each government $\mathrm{j}$ announces a "package” $\left\{T_{1}^{j}, T_{2}^{j}, \alpha_{1}^{j}, \alpha_{2}^{j}\right\}$ consisting of lump sum taxes (T’s) and a vector of performance requirements $\left(\alpha^{\prime} s\right)$. These announcements are simultaneous. After these announcements, each firm i chooses a location. The location choices can be made either simultaneously or sequentially. After both firms choose a location, they simultaneously choose an action $x_{i}$ for $\mathrm{i}=1,2 .{ }^{1}$

Note that $x_{i}{ }^{\prime} s$ can represent a vector of choices, although we treat them as scalars for ease of exposition. Each action can represent a production level, the purchase of domestic inputs, choice of technology, the quantity of exports, pollution levels, and so on. If a performance requirement is specified in jurisdiction $\mathrm{j}$, then if firm i locates in $\mathrm{j}$, its problem involves choosing $x_{i}$ to maximize

$$
\pi_{i}^{j}\left(x_{i}, x_{-i}, \alpha_{i}^{j}, T_{i}^{j}\right)=R_{i}^{j}\left(x_{i}, x_{-i}, \alpha_{i}^{j}\right)-T_{i}^{j}
$$

\footnotetext{
${ }^{1}$ If the choices of actions are sequential, we find identical equilibrium results.
} 
The first order condition to which involves

$$
\frac{\partial \pi_{i}^{j}\left(x_{i}, x_{-i}, \alpha_{i}^{j}, T_{i}^{j}\right)}{\partial x_{i}}=\frac{\partial R_{i}^{j}\left(x_{i}, x_{-i}, \alpha_{i}^{j}\right)}{\partial x_{i}}=0
$$

Each firm's first order condition implicitly defines a best response function, $x_{i}=x_{i}\left(x_{-i}, \alpha_{j}^{i}\right)$. We assume that the best response functions are continuous and monotonic in their arguments, and that the $\alpha_{j}^{i}{ }^{\prime} s$ constitute sufficient instruments such that the jurisdictions may achieve any desired output pair $\left\{x_{i}, x_{-i}\right\}$. Henceforth, to simplify the exposition, we shall treat the output pair $\left\{x_{i}, x_{-i}\right\}$ as the governments' choice variables and suppress the instruments $\alpha_{j}^{i}$. Note that we do not make any assumptions on the crosspartial derivatives of $R_{i}^{j}\left(x_{i}, x_{-i}\right)$. Thus, our framework allows for both positive and negative spillovers between firms. Examples of positive spillovers include technological synergies or labor market linkages, while a negative spillover could arise from competitive interaction in an oligopolistic market as in Lahiri and Ono (1998). While there is a host of work on the effects of FDI which can be used to detail our $\mathrm{R}^{\mathrm{j}}$ functions, we intentionally remain agnostic about their specificities in order to make the broadest case for our results.

With this setup, firm $\mathrm{i}$ will locate in jurisdiction $\mathrm{j}$ if:

$$
\pi_{i}^{j}\left(x_{i}\left(x_{-i}\right), x_{-i}, T_{i}^{j}\right) \geq V_{i}
$$

where $V_{i}$ is firm i's best outside option. This outside option could be to locate in the other jurisdiction or to not invest at all. To ease exposition we normalize the firm's payoffs without investment to zero.

Governments choose their packages to maximize national welfare, which for jurisdiction $\mathrm{j}$ is given by:

$$
W^{j}=G^{j}\left(x_{i}, x_{-i}\right)+\sum_{i} T_{i}^{j}
$$

where $\mathrm{G}^{\mathrm{j}}$ represents the non-tax gains that accrue to the host from foreign direct investment. In Lahiri and 
Ono (1998), this could consist of price-reducing competition and employment gains. In Haaland and Wooton (1999), the gain to the host arises because the multinational firms purchase intermediate inputs from domestic firms. This increase in demand increases the number of intermediate input varieties and reduces the average cost of their production. Thus, the amount of intermediate goods purchased by multinationals benefits the host through both employment increases and production-cost reductions. As with the $\mathrm{R}^{\mathrm{j}}$ functions, the specific form of $\mathrm{G}^{\mathrm{j}}$ depends on the situation at hand, however, we do not make any assumptions regarding the behavior of $\mathrm{G}^{\mathrm{j}}$ in its arguments. In fact, our general framework even allows for $\mathrm{G}^{\mathrm{j}}$ to be declining in the firms' actions, as it might, for example, if firms were polluting. We do, however, make the following two assumptions:

Assumption 1 (Beneficial FDI): For each jurisdiction j there exists $\left\{x_{1}, x_{2}\right\}$ such that:

$$
G^{j}\left(x_{1}, x_{2}\right)+\sum_{i} R_{i}^{j}\left(x_{i}, x_{-i}\right)>G^{j}(0,0)
$$

Assumption 2 (Agglomeration): There exists $\left\{x_{1}^{*}, x_{2}^{*}\right\}$ such that for any other $\left\{x_{1}, x_{2}\right\}$ :

$$
\begin{array}{r}
G\left(x_{1}^{*}, x_{2}^{*}\right)+G(0,0)+\sum_{i} R_{i}\left(x_{i}^{*}, x_{-i}^{*}\right)>\operatorname{Max}\left\{G\left(x_{1}, x_{2}\right)+G(0,0)+\sum_{i} R_{i}\left(x_{i}, x_{-i}\right),\right. \\
\left.G\left(x_{1}, 0\right)+G\left(0, x_{2}\right)+R_{1}\left(x_{1}, 0\right)+R_{2}\left(0, x_{2}\right)\right\}
\end{array}
$$

Assumption 1 guarantees that there exists a pair of activity levels $\left\{x_{1}, x_{2}\right\}$ such that there exist taxes under which both a jurisdiction and at least one firm will find investment mutually beneficial. If this assumption fails, the problem is trivial since no competition for the firm(s) exists. Note that this implies the existence of a pair of activity levels which increase global welfare (the sum of the countries welfares and firms' profits) over the no-investment level. Assumption 2 indicates that there exists a unique pair of activity levels such that, when the firms locate in the same jurisdiction, global welfare is maximized. With identical jurisdictions, it is irrelevant which of the locations is the host. Notice that this assumption does 
allow for an unwanted firm (represented by $x_{i}^{*}=0$ ), that is a firm which lowers global surplus if it invests. This agglomeration assumption in not necessary for our results, but does permit the simplest presentation of our main result. In any case, we relax the agglomeration assumption in Section III. It is important to recognize that without government intervention there are a host of situations in which neither the firms' locations nor their chosen actions will be socially optimally. For example, suppose that there are positive spillovers between the firms. Here, firms will choose action levels which are inefficiently low, as they do not internalize all of the benefits arising from their choices. Thus, without some coordination, there exist unrealized gains from FDI activity. Alternatively, firms may ignore the impact of their activity on the host, again leading to inefficient choices. Finally, it is easy to find situations in which firms do not agglomerate even though with proper coordination it is optimal for them to do so. These situations imply that even if governments have tax policies at their disposal, this policy instrument alone will not reach the global welfare maximum. As shown in our first proposition, performance requirements can alleviate this difficulty.

Proposition 1: A jurisdiction j's optimal strategy is to choose

$$
\left\{T_{1}^{j}, T_{2}^{j}, x_{1}^{j}, x_{2}^{j}\right\}=\left\{\pi^{1}\left(x_{1}^{*}, x_{2}^{*}\right)-V^{1}, \pi^{2}\left(x_{1}^{*}, x_{2}^{*}\right)-V^{2}, x_{1}^{*}, x_{2}^{*}\right\}
$$

Proof: By equation (3), a jurisdiction's welfare is strictly increasing in the tax revenues it collects.

Therefore, it will choose the highest taxes it can while still inducing the firm to invest in it. This implies that the host will choose a tax policy that makes the firm indifferent between locating there and exercising its outside option, hence equation (2) hold with equality. ${ }^{2}$ Plugging this result into (3) yields:

\footnotetext{
${ }^{2}$ We assume that if a firm is indifferent between locations, it will locate in jurisdiction 1 . Without such a tie-breaking rule, it is well known that mixed strategy equilibria can exist, however, in the interest of brevity we eliminate them.
} 


$$
W^{j}=G^{j}\left(x_{1}, x_{2}\right)+\sum_{i}\left[R_{i}\left(x_{i}, x_{-i}\right)-V_{i}\right]
$$

By the agglomeration assumption, the values of $\mathrm{x}_{1}$ and $\mathrm{x}_{2}$ which maximize (4) are $\mathrm{x}_{1}{ }^{*}$ and $\mathrm{x}_{2}{ }^{*}$. This yields the above as the jurisdiction's optimal strategy.

Q.E.D.

This strategy accomplishes two things. First, it chooses taxes that appropriate as much surplus as possible for the host. The firm-specific tax which does this is decreasing in that firm's outside option. Second, it chooses a performance requirement that maximizes the available surplus which can be split between the host and the firms. Under the agglomeration assumption, this also maximizes global welfare. This is because under the jurisdiction's optimal tax policy, it internalizes all of the spillovers from the firms' choices. Since the values of outside options are exogenous to jurisdictions, this amounts to maximizing global surplus.

It is instructive to compare this optimal policy with that derived by Lahiri and Ono (1998). In that paper, the authors consider a profit tax applied to foreign firms in the jurisdiction. While this does not alter a firm's behavior for a given number of firms in the market, it does affect the number of firms present. Thus the profit tax indirectly affects firms' activities. In a similar way, our lump sum taxes do not affect firm behavior for a given number of firms, however, since lump sum taxes do affect the profitability of investment, they can affect the number of firms that enter. As a result, they can have a comparable indirect impact on firm unrestricted actions. A key difference between their setup and ours is that Lahiri and Ono restrict the profit tax to be the same for all foreign firms whereas we allow the lump sum tax to differ across firms. Justification for our approach is provided by King, McAfee, and Welling (1993), who show that subsidies often differ across firms. Because of this additional degree of freedom, the jurisdiction may choose to offer one firm a subsidy while taxing another. Thus, Lahiri and Ono's condition for positive taxation need not hold here. Also, although we model the tax as lump sum, we can achieve identical results using a distortionary tax such as a payroll tax. This is because the government 
can simply adjust its performance requirement along with the distortionary tax in order to achieve the same firm action.

With the jurisdictions' strategies in hand, it is straightforward to deduce their equilibrium payoffs after competition in taxes and performance requirements.

Proposition 2: In the equilibrium of the tax and performance requirement setting game, $W^{j}=W^{-j}=G(0,0)$

Proof: Since governments simultaneously choose their tax and performance requirement packages, and since they take the overseas packages as given, they therefore treat the firms' outside options as constant. This leads them to bid the packages described by Proposition 1. Note that the performance requirement is not dependent upon either the tax package or the outside option. This is the same for both jurisdictions, thus $\left\{x_{1}^{j}, x_{2}^{j}\right\}=\left\{x_{1}^{-j}, x_{2}^{-j}\right\}=\left\{x_{1}^{*}, x_{2}^{*}\right\}$

As is common in games of tax competition for discrete firms, tax competition amounts to a second-price auction for firms. ${ }^{3}$ Alternatively, competition can be understood as a form of Bertrand competition in which each jurisdiction undercuts the other by offering marginally more attractive taxes to the firms. For given performance requirements, this drives taxes down until the losing jurisdiction no longer prefers to offer a lower tax (i.e. a higher bid) and win with certainty. This implies that its welfare is that which it achieves in the absence of the firms, or $\mathrm{G}(0,0)$. In a symmetric equilibrium this implies that $W^{j}=W^{-j}=G(0,0)$

Thus, as with many tax competition games, competition between jurisdictions leads to a "race to the

\footnotetext{
${ }^{3}$ See Fudenberg and Tirole (1993) for details on second-price auctions.
} 
bottom" in which all the gains from FDI are transferred to the firms. Early versions of the "race to the bottom" are presented by Zodrow and Mieszkowski (1986) and Wilson (1986). Additional examples are discussed in the surveys of Wildasin (1986) and Wilson (1999). It is important to note that a key difference between those models and ours is that they model competition for a continuous amount of investment rather than for discrete firms. In models with continuous investment, equilibria are usually characterized by an equilibrium in which the government retains some of the gains from investment yet taxes are inefficiently low and a public good is underprovided. With discrete firm locations, we find the typical equilibrium for a second-price auction in which the equilibrium bid makes the loser indifferent between winning and losing. This result is comparable to the discrete firm location models of Black and Hoyt (1989), King and Welling (1992), and King, McAfee, and Welling (1993). It is interesting to note that Devereux, Lockwood, and Redoano (2001) find that OECD tax data is consistent with governments competing for discrete firms. Despite this difference in the form of their equilibria, tax competition models for either continuous investment or discrete firms share a similar intuitive result: as jurisdictions compete for mobile capital, taxes are bid down to a level at which no jurisdiction will gain from a change in taxes which spurs an additional capital inflow. With identical jurisdictions and the preferences described by (3), the equilibrium tax package transfers all the gains from FDI to the firms and leaves the host indifferent between winning and losing. One interesting feature of the equilibrium is that it maximizes total surplus. Alternatively expressed this result says that the jurisdiction which can generate the greatest gains from FDI is also the one that wins the firms.

A second important difference between the Zodrow-Mieszkowski/Wilson model and ours is that here taxes enter national welfare linearly. Therefore our taxes are purely redistributive. As a result, any combination of taxes is socially efficient. This is in contrast to the standard models of tax competition in which taxes are used to provide a public good. As noted above, in those models equilibrium taxes are too low, implying that the public good is underprovided. If we were to include a public good in our model, 
we would also find that equilibrium taxes are inefficiently low. However, since the gains from coordination through performance requirements would remain, so would their equilibrium use. In fact, as long as the agglomeration assumption is maintained, we would still find that in equilibrium, firms will agglomerate and performance requirements will be set such that $\left\{x_{1}^{j}, x_{2}^{j}\right\}=\left\{x_{1}^{-j}, x_{2}^{-j}\right\}=\left\{x_{1}^{*}, x_{2}^{*}\right\}$. This is again because the jurisdiction that can elicit the greatest gains from FDI is able and willing to outbid the other. Note that if the public good is necessary in consumption and mobile firms represent the only possible source of tax revenues, then the agglomeration assumption would be violated and a social planner would not choose to locate the firms together. We discuss this alternative in Section III.

We now turn our attention to the distribution of the surplus, which depends crucially upon whether the firms enter simultaneously or sequentially.

Proposition 3: In the equilibrium of the tax and performance requirement setting game, firm payoffs $\left\{\pi_{1}, \pi_{2}\right\}$ are described by:

a) A continuum $\sum_{i} \pi_{i}=G\left(x_{1}^{*}, x_{2}^{*}\right)-G(0,0)+\sum_{i} R_{i}\left(x_{i}^{*}, x_{-i}^{*}\right)$ such that $\pi_{1} \geq \underset{x_{1}}{\operatorname{Max}_{1}}\left\{R_{1}\left(x_{1}, 0\right)+G\left(x_{1}, 0\right)-G(0,0)\right\}$ and $\pi_{2} \geq \underset{x_{2}}{\operatorname{Max}}\left\{R_{2}\left(0, x_{2}\right)+G\left(0, x_{2}\right)-G(0,0)\right\}$ if firms enter simultaneously, or b) $\pi_{1}=G\left(x_{1}^{*}, x_{2}^{*}\right)-G(0,0)+\sum_{i} R_{i}\left(x_{i}^{*}, x_{-i}^{*}\right)-\pi_{2}$ and $\pi_{2}=\operatorname{Max}_{x_{2}}\left\{R_{2}\left(0, x_{2}\right)+G\left(0, x_{2}\right)-G(0,0)\right\}$ if firms enter sequentially.

Proof: When firms agglomerate, it must be that neither would prefer to enter the other jurisdiction alone. Since, in addition to the surplus that accrues directly to the individual firm, a firm would be able to extract the gain which the other jurisdiction would experience through tax revenues, this yields the lower bounds 
on firm payoffs described above. With simultaneous entry, the division of surplus is akin to a "split the dollar" game, which results in a continuum of payoffs as described in a). Note that it is not possible for the losing jurisdiction to offer firms a different division of payoffs and attract them since it will not offer

them more than $G\left(x_{1}^{*}, x_{2}^{*}\right)-G(0,0)+\sum_{i} R_{i}\left(x_{i}^{*}, x_{-i}^{*}\right)$ in total. When firms enter sequentially, the firm that enters second gets exactly the value of its outside option, which is given by the maximum amount of surplus it could extract if it chose to enter the jurisdiction that did not attract the first firm. A jurisdiction will not offer any more than this since doing so makes it worse off than if it had no investment at all. The first firm earns more than its outside option since it has a first mover advantage. In fact, after paying both the jurisdiction and the second firm their outside options, all remaining surplus is extracted by the first firm through tax subsidies.

Q.E.D.

Regardless of the sequence of entry, the firms jointly extract the entire surplus generated by FDI. The division between them depends on the whether a firm has a first mover advantage. It is important to note that neither firm loses by the imposition of performance requirements. In fact, since global welfare increases with their use, at least one firm strictly prefers the use of such requirements. Therefore, in equilibrium, we find that our theory matches the observations made by Graham (2000) and others that locations both offer favorable tax packages and impose performance requirements.

As we demonstrate in the next section, the flavor of this equilibrium is retained under a variety of alternative assumptions.

\section{Extensions}

Although the above results were derived with very few assumptions regarding the properties of the profit or benefit functions, it is natural to question how general they are. On the whole, we find that the main intuition is quite robust. This is because of the nature of the tax competition. As noted above, 
tax competition for discrete firms amounts to a second-price auction. Since performance requirements will simply be used to maximize the gains from FDI, the primary difficulty in extending the model comes in questioning how the extensions will affect the equilibrium of a second-price auction. For our first extension, we consider asymmetric jurisdictions and alter the agglomeration assumption such that there exists a pair of firm activity levels $\left\{x_{1}^{{ }^{j} j}, x_{2}^{*_{j}}\right\}$ for which, when the firms locate in jurisdiction $\mathrm{j}$ and undertake these actions, global welfare is maximized. This simply refines the previous assumption by stating that global welfare maximization requires that the optimal activity levels take place in the optimal location. Since jurisdiction $\mathrm{j}$ has more surplus at its disposal than the other jurisdiction, it will win the bidding war for the firms. Thus, in equilibrium the losing jurisdiction gets $G^{-j}(0,0)$ while the firms will split the surplus $G^{-j}\left(x_{1}^{*-j}, x_{2}^{*-j}\right)-G^{-j}(0,0)+\sum_{i} R_{i}^{-j}\left(x_{i}^{*-j}, x_{-i}^{*-j}\right)$, which is the most that they could receive if they located in the losing jurisdiction. The split of this surplus depends on the sequence of firm entry in a manner similar to Proposition 3. This leaves jurisdiction $\mathrm{j}$ with

$$
G^{j}\left(x_{1}^{* j}, x_{2}^{* j}\right)+\sum_{i} R_{i}^{j}\left(x_{i}^{* j}, x_{-i}^{* j}\right)-\left[G^{-j}\left(x_{1}^{*-j}, x_{2}^{*-j}\right)-G^{-j}(0,0)+\sum_{i} R_{i}^{-j}\left(x_{i}^{*_{-j}}, x_{-i}^{*_{-j}}\right)\right]
$$

which by the modified agglomeration assumption is strictly greater than $G^{j}(0,0)$. Thus, with asymmetry, we again find that performance requirements will elicit global welfare maximizing levels of firm activity. Now, however, the winning jurisdiction is able to retain some of the gains from FDI as is standard in second-price auctions with heterogeneous valuations.

With multiple jurisdictions, we again find that the jurisdiction which generates the greatest surplus from FDI will win the firms. Without loss of generality, label the jurisdictions $j=1,2,3 \ldots$ and so on such that when firms operate at the welfare maximizing levels in each jurisdiction, global welfare is highest when they locate in $j=1$, second highest when they locate in $j=2$, etc. Since location 2 has the second most surplus available for bidding, location 1 must match location 2's bid to win the firms. This 
leaves 1 with the surplus described by (5), and exceeds $G^{1}(0,0)$. All other jurisdictions $j \neq 1$

receive $G^{j}(0,0)$. Again, these results follow directly from the auction nature of tax competition. Firms will split $G^{2}\left(x_{1}^{* 2}, x_{1}^{* 2}\right)-G^{2}(0,0)+\sum_{i} R_{i}^{2}\left(x_{i}^{* 2}, x_{-i}^{* 2}\right)$ according to the sequence of entry. Therefore once again firms' locations and actions maximize global surplus in equilibrium.

With multiple firms we extend the agglomeration assumption such that global surplus is maximized when all $\mathrm{N}$ firms locate in $\mathrm{j}=1$ and operate at $\left\{x_{1}^{* 1}, x_{2}^{* 1}, \ldots, x_{N}^{* 1}\right\}$. In this case, the sum of the firms' payoffs is the difference between the maximum surplus they would have generated in 2 less $G^{2}(0,0, \ldots .0)$. The division of this surplus among firms depends on the order in which they enter. As in Proposition 3, if there is sequential entry the final firm receives only what it would have earned if it located by itself in another jurisdiction. Additionally, the division of surplus must be in the core, that is there does not exist a coalition of firms which can break off and go to another jurisdiction where they can receive subsidies and requirements giving them higher profits. A non-empty core is guaranteed by the extended agglomeration assumption. Again, if global welfare is strictly higher when firms locate in 1 than when they operate in 2 , then location 1 is better off in the equilibrium than if it did not host the firms. Thus, once again, the equilibrium packages result in maximized global surplus.

As in Lahiri and Ono (1998), we can extend our analysis to include both immobile domestic firms and mobile multinational firms. We can subsume the immobile firms into the $G($.$) and R($.$) functions,$ which transforms this situation into the one above where only the mobile firms are explicitly modeled. Therefore all of our results hold even in the presence of immobile firms. In this way, Lahiri and Ono's setting can be framed as a special case of our more general framework. Note that since domestic firms may not internalize all of the effects of their actions, a host may also desire to implement domestic industrial policies to correct for unrealized gains from domestic investment. If such policy tools are available, then the same incentives which drive requirements that implement optimal mobile firm choices 
will also yield comparable requirements for domestic firms.

Finally, we relax the agglomeration assumption. One special case in which the agglomeration assumption fails is when mobile firms represent the only possible source of revenue which is needed to provide a necessary public good. Instead, assume that there exists a distribution of firms across jurisdictions such that when the $\mathrm{N}$ firms operate at $\left\{x_{1}^{*}, x_{2}^{*}, \ldots, x_{N}^{*}\right\}$ then the gains from FDI are maximized. If taxes are needed to provide a public good, this distribution simply maximizes the available surplus which could be distributed between all of the agents in all of the jurisdictions. As long the space of possible global welfares is compact, the existence of such a maximizing distribution is ensured. Once again, we find that there is an equilibrium that yields exactly this distribution and set of activity levels. This equilibrium must be in the core, with jurisdictions paying their firms enough such that it is not individually rational for any other jurisdiction to offer any subset of firms enough to induce them to change their location. Again, as long as there exists such an optimal distribution and action set, the core will be non-empty. ${ }^{4}$ Thus, there exists a combination of taxes by the current hosts which allows them to retain their firms (and possibly some of the additional surplus generated) such that the competing jurisdictions are unwilling to further increase the total subsidies they offer to this subset of firms. Therefore, there exists a Nash equilibrium in packages which yields this distribution of firms and elicits their global welfare maximizing activity levels. However, similar to the literature on competition for continuous investment levels, tax rates may be too low in equilibrium due to competition. Thus although the gains from FDI will be maximized in equilibrium, they may be inefficiently allocated between firm profits, private consumption, and public good provision.

${ }^{4}$ It is important to recognize the importance of firm-specific taxes for this result. If jurisdictions are constrained to identical taxes for all firms, they may not choose to attract the firms called for by the surplus-maximizing distribution. 


\section{Conclusion}

In the scramble for foreign direct investment (FDI), jurisdictions often compete with one another by offering multinational firms tax subsidies if they locate within their borders. Since firms find taxes burdensome, this can lead towards a race to the bottom in which large tax subsidies are offered. At the same time, however, jurisdictions link these subsidies to performance requirements such as domestic content restrictions. Since firms presumably find these restrictions burdensome as well, why these performance requirements are not competed away presents a mystery. We resolve this issue by demonstrating that performance requirements can act as a coordination device that maximizes the gains from FDI. Since this allows firms to extract even more from jurisdictions through tax subsidies, they find this external coordination beneficial. We show that in a game in which jurisdictions offer packages of taxes and performance requirements the equilibrium involves binding requirements which are Pareto optimal. This result is robust to a variety of assumptions on the number of firms, jurisdictions, and optimal distribution of firms across the jurisdictions.

One admitted limitation of our analysis is that we do not permit spillovers between jurisdictions. Thus, we do not allow for scenarios such as cross-border pollution. Rauscher (1995) considers the case of transfrontier pollution from the production of a mobile monopolist. Low host taxes encourage additional production (and thus lower prices for the monopolist's good) while simultaneously encouraging damaging pollution. As a result, he finds that equilibrium taxes can be too high or too low relative to the global welfare maximizing solution. Similarly, if potential hosts do not internalize all of the effects of FDI in our model due to inter-jurisdictional spillovers, then the equilibrium packages of taxes and performance requirements many not result in the global welfare maximizing distribution of firms and activities. Nevertheless, it is simple to calculate examples in which binding performance requirements are imposed in such a second-best equilibrium. Thus, although a social planner may be able to enact a Pareto 
improvement by using side payments, the second-best Nash equilibrium can still involve the use of performance requirements. Furthermore, if the global welfare function is concerned about the distribution of surplus across regions, side payments between jurisdictions may be necessary to obtain a first-best solution even if social welfare-maximizing performance requirements are imposed. A second limitation of the above model is that it is static. As found by King, McAfee, and Welling (1993), when there are multiple periods and a firm can relocate between jurisdictions, the firm may locate in an inefficient location because of the effect this has on bidding in the following round. As the authors note, this firm strategy does not work in a one-period model and therefore it does not arise in the present context. Again, however, it is not difficult to find situations in which performance requirements are used in a more complex dynamic setting even if the equilibrium is not fully efficient.

Despite these limitations, our results make two contributions to the literature on competition for foreign direct investment. First, we have demonstrated that performance requirements such as domestic content restrictions can coordinate firms and increase the gains from foreign direct investment. This increase results from interactions between firm choices and the rents generated by other firms and the host jurisdiction. Second, we have presented the first model of competition in performance requirements for multinational firms. In our analysis, we have been intentionally non-specific about the form of these spillovers and the policy tools which affect them in order to make our results applicable to a variety of situations. By demonstrating their equilibrium use we hope that this motivates additional investigation into creation and implementation of such policy tools. 


\section{References}

Black, Dan A. and Hoyt, William H. (1989) “Bidding for Firms.” American Economic Review, 79:5, pp. 1249-1256.

Caves, Richard E. (1996), Multinational Enterprise and Economic Analysis, Second Edition, Cambridge University Press, New York, New York.

Devereux, Michael P., Ben Lockwood, and Michela Redoano (2001), "Do countries compete over corporate tax rates?" Mimeo.

Fudenberg, Drew and Jean Tirole (1993), Game Theory, The MIT Press, Cambridge, Massachusetts.

Fung, Michael Ka-Yiu (1994), "Content protection, resource allocation, and variable labour supply," Canadian Journal of Economics, 27:1, pp. 175-82.

Graham, Edward M. (2000), Fighting the Wrong Enemy: Antiglobal Activists and Multinational Enterprises, Institute for International Economics, Washington D.C..

Grossman, Gene M. (1981), "The theory of domestic content protection and content preference," Quarterly Journal of Economics, 96:4, pp. 583-603.

Haaland, Jan and Wooton, Ian (1999), "International competition for multinational investment," Scandinavian Journal of Economics, 101:4, pp. 631-649.

Helleiner, G. K. (1989), “Transnational corporations and direct foreign investment," in H. Chenery and T. N. Srinivasan (eds.), Handbook of Development Economics, Vol. 2, pp. 1441-80, North-Holland, Amsterdam.

King, Ian, McAfee, R. Preston and Welling, Linda (1993), "Industrial blackmail: dynamic tax competition and public investment." Canadian Journal of Economics, 26:3, pp. 590-608.

King, Ian and Welling, Linda. (1992), "Commitment, Efficiency, and Footloose Firms." Economica, 59:223, pp. 63-73.

Lahiri, Sajal and Yoshiyasu Ono (1998), "Foreign direct investment, local content requirement, and profit taxation," Economic Journal, 108, pp. 444-457.

Madan, Vibhas (1998), “Transfer prices, tariffs, and content restrictions,” Review of International Economics, 6:4, pp. 625-637.

Ministry of International Trade and Industry (2000), Report on the WTO Consistency of Trade Policies by Major Trading Partners, Government of Japan, Tokyo.

Moran, Theodore H. (1998), Foreign Direct Investment and Development: The New Policy Agenda for Developing Countries and Economies in Transition, Institute for International Economics, Washington. 
Okamoto, Yumiko (1999), "Multinationals, production efficiency, and spillover effects: the case of the U.S. auto parts industry," Weltwirtschaftliche Archiv, 135:2, pp. 241-260.

Rauscher, Michael (1995), "Environmental regulation and the location of polluting industries," International Tax and Public Finance, 2:2, pp. 229-244.

Richardson, Martin (1991), "The effects of a content requirement on a foreign duopsonist," Journal of International Economics, 31:1-2, pp. 143-55.

Wildasin, D. E (1986), Urban Public Finance, Harwood Academic Publishers, New York.

Wilson, John (1986), "A theory of interregional tax competition," Journal of Urban Economics, 19, pp. 296-315.

Wilson, John D. (1999), “Theories of tax competition,” National Tax Journal, 52:2, pp. 269-304.

Zodrow, George R. and Peter Mieszkowski (1986), "Pigou, Tiebout, Property taxation, and the underprovision of local public goods," Journal of Urban Economics, 19:3, pp. 356-370. 